\title{
How much walking should be advocated for good health in adolescent girls?
}

*Mhairi MacDonald ${ }^{1}$, Samantha Fawkner ${ }^{2}$, Ailsa Niven ${ }^{2}$

${ }^{1}$ Dundee Academy of Sport, Abertay University, Dundee, Scotland, ${ }^{2}$ Physical Activity for Health Research Centre, University of Edinburgh, Edinburgh, Scotland

*Corresponding Author: M.MacDonald@abertay.ac.uk

This is the accepted author manuscript reprinted, by permission, from Journal of Physical Activity and Health, 2016, http://dx.doi.org/10.1123/ipah.20150391. (C) Human Kinetics, Inc. 
How much walking should be advocated for good health in adolescent girls?

Brief running head: Walking for health

Manuscript type: Original research

Keywords: Youth, Physical activity, Step count

Abstract word count: 192 words

Manuscript word count: 5861 words

Date of submission: $10^{\text {th }}$ August 2015

Date of resubmission: $11^{\text {th }}$ July 2016 


\begin{abstract}
Background: It is currently not known how much walking should be advocated for good health in adolescent girls. The aim of this study was therefore to recommend health referenced standards for step defined physical activity relating to appropriate health criterion/indicators in a group of adolescent girls.
\end{abstract}

Method: Two hundred and thirty adolescent girls aged between 12-15years volunteered to take part in the study. Each participant undertook measurements (BMI, waist circumference, $\%$ body fat and blood pressure) to define health status. Activity data were collected by pedometer and used to assess daily step counts and accumulated daily activity time over seven consecutive days.

Results: Individuals classified as 'healthy' did not take significantly more steps·day ${ }^{-1}$ nor spend more time in moderate intensity activity than individuals classified as at health risk or with poor health profiles.

Conclusion: 'Healthy' adolescent girls do not walk significantly more in term of steps·day-1 or time spent in activity than girls classified as 'unhealthy'. This could suggest that adolescent girls may not walk enough to stratify health and health related outcomes and as a result the data could not be used to inform an appropriate step guideline for this population.

\title{
Background
}

Existing physical activity guidelines state adolescents should engage in at least 60 minutes and up to several hours of moderate to vigorous physical activity (MVPA) everyday. ${ }^{1}$ At present $84 \%$ of adolescent girls are insufficiently active, which has serious implications for their current and future health ${ }^{1,2}$ and strategies are required in order to address this. Walking is recognised as an effective way of implementing regular, health enhancing physical activity 
into the daily routine of the general population. ${ }^{3,4,5}$ In an adolescent population walking is a convenient alternative to active play and sports participation, and walking has been demonstrated to be of sufficient intensity to contribute to accumulated MVPA. ${ }^{6}$ Consequently, guidelines as to the number of steps $\cdot$ day $^{-1}$ that should be advocated to maintain good health have been published. For example, in adults 10,000 steps $^{\cdot}$ day $^{-1}$ is considered sufficient to maintain health. ${ }^{6-9}$ However in the youth population there is conflicting evidence with regard to the number of daily steps $\left(\right.$ steps $^{\prime} \cdot$ day $^{-1}$ ) required. Normative data suggest that among children (typically 5-11yrs) we can expect 10-13,000 steps $\cdot$ day $^{-1}$ for girls' and 12-16,000 steps $\cdot$ day $^{-1}$ for boys, ${ }^{10}$ and during adolescence (1219yrs) these step values steadily decline to $8-9,000$ steps $\cdot$ day ${ }^{-1}$, especially among adolescent girls. ${ }^{6,11}$ However these expected values do not represent optimal daily step targets ${ }^{7,12}$ or inform how much walking should be advocated for good health.

Whilst the PA recommendations for adolescents (up to 18 years of age) are the same for children (from the age of 5) the examination of step count data has the potential to provide specific guidelines that are gender and population specific. Five youth studies have proposed daily step recommendations that relate to specific health criterion/indicators. $10,000-13,000$ steps $\cdot$ day $^{-1}$ for girls and 13,000-16,000 steps $\cdot$ day $^{-1}$ for boys have been associated with healthy body composition defined by body mass index (BMI) ${ }^{13,14}$ and percentage body fat $(\% \mathrm{BF}) .{ }^{12}$ However, these proposed health referenced recommendations have been established in children age 5-12years and are therefore not necessarily appropriate for adolescents.12, 14, 15 
Dollman et al., ${ }^{16}$ and McCormack et al., ${ }^{17}$ have included adolescents in their recommendations. McCormack et al., ${ }^{17}$ proposed a single health referenced recommendation (defined by BMI and developed using contrasting group method) of 16,000 steps $\cdot$ day $^{-1}$ for both boys and girls aged 7-16yrs. Although this recommendation may be useful for health promotion purposes, it is not an adolescent specific recommendation. Alternatively Dollman et al., ${ }^{16}$ examined health referenced recommendations in four age and gender groups (5-12yr old girls and boys and 13-16yr old girls and boys) allowing for adolescent specific recommendations to be proposed. $11,000 \mathrm{steps} \cdot \mathrm{day}^{-1}$ was associated with healthy body composition defined by BMI in 13-16yr old boys. However among adolescent girls daily step values did not discriminate between individuals classified as healthy or at health risk as defined by BMI (e.g. healthy weight vs overweight/obese). It therefore remains unclear as to the number of daily steps required for health in adolescent girls.

A major limitation of these studies is a reliance on BMI, (other than one study that has considered $\% \mathrm{BF})^{12}$ to demarcate between healthy and unhealthy status. The limitations of BMI as a health indicator are well documented ${ }^{18}$, and therefore it may be prudent to consider other health indicators to demarcate between healthy and unhealthy young people in identifying step guidelines.

Further, there are currently no step based data relating to time in activity (i.e., active stepping at an intensity equivalent to moderate) that relate to specific health criterion/indicators and thus health status. Given that health benefits are gained from moderate to vigorous activity ${ }^{1}$, and that new generation pedometers can now record stepping activity at or above prespecified levels of intensity, the consideration of time spent in active stepping may also be important. 
The aim of this study was therefore to i) contribute to the evidence for health referenced standards for step defined (walking) physical activity (daily steps and activity time) relating to appropriate health criterion/indicators (BMI, waist circumference (WC), \%body fat (BF) and blood pressure (BP)) in a group of adolescent girls, ii) explore whether daily step counts and/or activity time is more important for health, and iii) evaluate previously published step recommendations, concurrently identifying the prevalence of adolescent girls achieving them.

\section{Methods and Procedures}

\section{Participants}

Following Institutional ethics and local city council approval, informed parental and participant consent, adolescent girls ( $\mathrm{n}=230$; mean age $13.45 \pm 1.04 \mathrm{yrs})$ volunteered to take part in the study (see figure 1 for participant data and study flow). Data were collected in the following order: a) health indicators; b) activity data, collected by pedometer over seven consecutive days, both week and weekend days.

\section{Health indicators}

Stretch stature and body mass were measured using a Seca portable stadiometer and Seca flat scales (Seca 761, Seca Birmingham, UK). Waist circumference was measured at minimal waist site to the nearest millimeter, using a steel tape with participants in the standing position and at the end of expiration. All measurements were made according to the procedures recommended by the International Society for Advancement of Kinanthropometry $^{19}$. Body mass index (BMI) was calculated by dividing body mass in kilograms $(\mathrm{kg})$ by stature in meters ${ }^{2}\left(\mathrm{~kg} / \mathrm{m}^{2}\right)$.

Total body fatness was measured using the Tanita BC-418MA segmental body composition analyser (Tanita Corporation, Tokyo, Japan). Measurements were taken according to 
manufacturer's instructions; at least three hours after waking and after eating. Prediction equations converting resistance into body fat used by $\mathrm{McCarth} \mathrm{y}^{20}$ were provided by the manufacturer (Tanita Corporation, Tokyo, Japan). The standard error of estimate for girls was $2.8 \%$ body fat ${ }^{20}$.

Blood pressure was taken after a period of 5minutes rest and measured using an electronic (oscillometric) monitor, Omron-705IT (HEM-759-E, Omron Healthcare, Inc, Bannockburn, IL). Participants were seated and the appropriate sized cuff for the arm circumference was placed on the right arm. Participants were instructed to rest their arm on the table and relax.

Physiological changes, may impact on health measures such as body composition during natural growth and development, therefore maturation status was measured and reported as maturity offset (time before or after peak height velocity) and was predicted using the equation of Mirwald ${ }^{21}$

Maturity offset $=-9.376+0.0001882 \times($ leg length $\times$ sitting height $)+0.0022 \times($ age $\times$ leg length $)+0.005841 \times($ age $x$ sitting height $)-0.002658 \times$ (age $x$ weight $)+0.07693 x$ (weight/height x100)

\section{Activity data (step count measures)}

The New Lifestyles NL-1000 (New Lifestyles Inc, Lee's Summit, Missouri, USA) a uniaxial piezoelectric pedometer was used to assess daily step counts and accumulated daily activity time (e.g. time spent at or above a pre-specified intensity threshold (steps $\left.\cdot \mathrm{min}^{-1}\right)$ ) over seven consecutive days, both week and weekend days. The activity time threshold on each pedometer was set at the manufacturer's activity level 4, equivalent to 3.6 METs. 
All pedometers were attached to an elastic belt on the participants' waistband according to manufacturer's specifications; above the midline of the right knee. Participants were instructed to wear their pedometers at all times except when sleeping and during water based activities e.g. showering, swimming. All pedometers were sealed with tamper evident security tape (Tamper Technologies LTD).

In addition each participant was issued with a diary sheet and instructed to note down the time when they either forgot to attach or removed their pedometer for $>1 \mathrm{~h}$, along with a brief reason.

\section{Data treatment}

\section{Health indicators}

Gender and age appropriate cut points were used to classify participants as healthy $\left(>2^{\text {nd }}<\right.$ $90^{\text {th }}$ percentile) or unhealthy (at health risk) $\left(<2^{\text {nd }} \geq 90^{\text {th }}\right.$ percentile) according to each health indicator examined: $\mathrm{BMI}^{22}$, waist circumference ${ }^{23}$, and percentage body fat ${ }^{20}$. Blood pressure $^{24}$ cut points for children and adolescents, were used to classify participants as normotensive (non hypertensive/healthy) $\left(<90^{\text {th }}\right.$ percentile) or pre-hypertensive $\left(\geq 90^{\text {th }}<95^{\text {th }}\right.$ percentile), hypertensive stage $1\left(\geq 95^{\text {th }}<99^{\text {th }}\right.$ percentile $)$ and $2\left(\geq 99^{\text {th }}\right.$ percentile $)$ (unhealthy) by gender, age and height for both systolic and diastolic blood pressure.

In addition to each of the single health indicators, cluster risk scores were calculated by summing the Z-scores for each health indicator (as data were normally distributed). Two separate cluster scores were calculated to create two health profiles. The health profiles consisted of the following; profile 1 cluster score of BMI, WC and BP and profile 2, cluster score of $\% \mathrm{BF}, \mathrm{WC}$ and $\mathrm{BP}$. Individuals with a cluster score (health profile score) of $\pm 1 \mathrm{SD}$ of the mean were considered at health risk. 


\section{Activity data}

Pedometer step counts and activity time were taken as the average number of steps $\cdot$ day $^{-1}$ and mins $\cdot$ day $^{-1}$ respectively, when at least 4 days data (3 weekdays and 1 weekend) were available. ${ }^{25,26}$ Step counts and activity time were weighted according to the ratio of weekdays to weekends (to account for any bias between weekdays and weekend days). ${ }^{27}$ Steps were smoothed to 1000 step increments to allow for comparisons to be made to prior youth studies, ${ }^{13,17} 1000$ steps may considered to be approximately 10 mins of brisk walking, ${ }^{4}$ and the minimum requirement to obtain health benefits. ${ }^{28,29}$

Daily step counts $<1000$ or $>30,000$ were regarded as outliers ${ }^{30}$ and were subsequently excluded from further analysis. Daily step counts and corresponding activity time were also excluded where there was evidence that the pedometer had been tampered with or where participants indicated either non-attachment or removal of their pedometer for $>1 \mathrm{~h}$ on a given day (determined by self-report diary sheet).

\section{Data analysis}

Participants were classified as healthy and unhealthy for each single health indicator and profile as there were no meaningful differences when each category was further divided.

Prior to further analyses the data were tested for the assumption of parametric tests. While not all variables met these assumptions, subsequent $\log$ transformation of the data ${ }^{31}$ indicated no significant difference in the findings when using the log transformed or original data. Therefore, to ease interpretation, parametric tests were used for subsequent data analysis on the original data. ${ }^{31}$ The differences in mean daily step counts $\left(\right.$ steps $\cdot$ day $^{-1}$ ) and daily activity 
time (mins $\cdot$ day $^{-1}$ ) between participants classified as healthy and unhealthy were examined separately for each of the single health indicators (BMI, WC, \%BF and BP) and health profiles (HP) and compared using independent sample t-tests and effect sizes are reported.

Pearson correlations were used to explore bivariate associations between health status defined by each health indicator and health profile (cluster risk score), maturation status, daily step counts $\left(\right.$ steps $\cdot$ day $\left.^{-1}\right)$ and daily activity time $\left(\right.$ mins $\cdot$ day $\left.^{-1}\right)$.

To establish health referenced standards for pedometer determined physical activity (step and activity cut points) relating to each health indicator and health profile, two separate analysis techniques were considered; the criterion referenced approach using the contrasting group method $^{32}$ and Receiver-operating characteristics (ROC) curves analysis. These methods have been used previously in similar youth studies and have been described in detail elsewhere. ${ }^{8}$, 14, 33 To evaluate previously published step recommendations the sensitivity (Se) and specificity ( $\mathrm{Sp}$ ) values were calculated for all currently published step count recommendations ${ }^{13,, 14,17,25,27}$ to evaluate their ability to correctly discriminate between healthy and unhealthy girls according to BMI and \%BF indicators and health profiles 1 and 2 . The percentage of girls (separated by age group e.g. 12, 13, 14 and 15yr olds) achieving previously published recommended steps $\cdot$ day $^{-1}$ were also calculated.

PASW Statistics version 18.0.0 (IBM Corp., Somers, NY, USA) was used for statistical analysis. Statistical significance was set at $p<0.05$. 


\section{Results}

\section{Descriptive results}

Figure 1 illustrates participant numbers recruited to the study, exclusion criteria and dropout rates. Complete pedometer data were available for 168 girls (73\%). There were no significant differences in age and stature between the girls included in pedometer analysis and those excluded (figure 1). However the girls that were excluded from further analysis weighed significantly more than the girls included in the analysis. Not all 168 girls completed all health indicator assessments. Table 1 presents descriptive data for their physical characteristics.

\section{Activity Analysis}

Table 2 presents the mean daily step counts $\left(\right.$ steps $^{\cdot} \cdot$ day $\left.^{-1}\right)$ and activity time (mins $\cdot$ day $\left.^{-1}\right)$ for each single health indicator (BMI, WC, \%BF and $\mathrm{BP}$ ) and health profile. The mean daily step count (steps $\cdot$ day $^{-1}$ ) and activity time (mins $\cdot$ day $^{-1}$ ) for the girls was $10287 \pm 2931$ steps and $39.49 \pm 18.26$ mins respectively. Although participants classified as 'healthy', took more steps $\cdot$ day $^{-1}$ and activity mins $\cdot d a y^{-1}$ than those classified as 'unhealthy', with the exception of the 'unhealthy' girls classified by the BP indicator (table 2), these results were not significant, small effect sizes $(\mathrm{d}=0.1-0.4)^{34}$ were also observed (table 2$)$. Therefore the fundamental requirements for application of the contrasting group method to establish criterion (health) referenced standards were not satisfied ${ }^{33}$ e.g. the assumption of the existence of dichotomised groups cannot be met. Similarly, results of the ROC analysis show the Area under the Curve was not significantly different from 0.5. Consequently cut points could not be determined for daily steps and activity time. 
Pearson correlations showed no significant relationship between health status and daily step counts (steps $\cdot$ day $\left.^{-1}\right)$, daily activity time $\left(\right.$ mins $\cdot$ day $\left.^{-1}\right)$ and maturation status for health defined by BMI, WC, \%BF, BP, HP1 and HP2 respectively (see table 5). Further no significant relationship was seen between maturation status and daily step counts (steps $\cdot$ day $\left.^{-1}\right)(r=-0.01$ $\mathrm{p}=0.925)$, and daily activity time $\left(\right.$ mins $\left.^{\prime} \cdot \mathrm{day}^{-1}\right)(\mathrm{r}=0.01 \mathrm{p}=0.865)$

\section{Comparison of current step recommendations}

A comparison of previously published step count recommendations for BMI, \%BF and HP1 (Cluster score of Body Mass Index, Waist Circumference and Blood Pressure) and HP2 (Cluster score of \% body fat, Waist Circumference and Blood Pressure) are presented in table 3. The step cut point of $10,000^{14}$ consistently produced the highest Se and Sp values, which were maximised best in HP1 when compared to the single health indicators of BMI, \% BF and HP2. The step cut point of $13,000{ }^{27}$ resulted in low Se and Sp values for both single and profile health indicators. The percentage of girls (separated into age groups of 12 ( $n=69), 13$, $(\mathrm{n}=38), 14(\mathrm{n}=47)$ and $15(\mathrm{n}=14)$ years $)$ achieving the recommended steps $\cdot$ day $^{-1}$ for each step cut point $^{13,14,17,25,27}$ are presented in Table 4. For all age groups at least 50\% achieved the recommendation of 10,000 steps $\cdot$ day $^{-1}$ (BMI-referenced cut point).${ }^{14}$ Only a small percentage (4\%) of the girls achieved the step recommendation of 16,000 steps $\cdot$ day $^{-1} \cdot{ }^{17}$

\section{Discussion}

In an attempt to inform how much walking should be advocated for good health in adolescent girls the current study has examined daily step counts and activity time values relating to different health indicators (BMI, WC, \%BF and BP) and 2 separate health profiles. Although daily step recommendations have previously been defined by BMI, in children and 
adolescents ${ }^{13,14,16,17}$ and \%BF in children, ${ }^{12}$ there are not currently any step

recommendations that specifically relate to adolescent girls. As well, these previous studies have relied on $\mathrm{BMI}$ and $\% \mathrm{BF}$ as indicators of health. This is the first study to attempt to identify step recommendations according to WC (included as a measure of abdominal adiposity) ${ }^{36}$ and BP (included as a measure of cardiovascular health) ${ }^{35}$ as single health indicators, and according to health profiles (cluster risk scores) of BMI, WC, \%BF and BP in an adolescent population.

\section{Adolescent appropriate health reference standards}

Results of the current study indicated that individuals classified as 'healthy' defined by each of the single health indicators and health profiles did not take significantly more steps $\cdot$ day $^{-1}$ or spend more time in moderate intensity activity than individuals classified as at health risk, or with poor health profiles. This is not consistent with the findings of prior youth studies, ${ }^{12}$, 13, 14, 16, 17 who reported that individuals with a healthy body composition defined by BMI ${ }^{13}$, $14,16,17$ and $\% \mathrm{BF}^{12}$ took more steps $\cdot$ day $^{-1}$ than their unhealthy counterparts. In the current study, the smallest difference between 'healthy' and 'unhealthy' girls was 442 steps·day-1 and 4 minutes activity time when health was defined by HP1. Although probably only equivalent to $400-500 \mathrm{~m}$ walking distance, in terms of energy expenditure this still relates to extra calories burned and more importantly a reduction in sedentary time. It is also likely that these small differences may be accumulated through incidental activity, which has been deemed to be equally important to achieving moderate to vigorous intensity activity targets. ${ }^{37}$ However, this study suggests it is unlikely that these small differences in walking behaviour might impact on health. The difference in steps and activity time between health groups was not sufficiently different for the application of the contrasting group method ${ }^{33}$ or the ROC analysis. These results suggest that daily step counts and activity time values do not 
discriminate between girls classified as 'healthy' or 'unhealthy'. The findings are consistent with those of Dollman et al., ${ }^{16}$ the only other study to consider adolescent girls as a separate subsample of the youth population with respect to evaluating 'healthy' walking behaviour.

Dollman et al., ${ }^{16}$ suggested that the poor association between steps $\cdot$ day $^{-1}$ and health status in adolescent girls may be attributed to changes in body composition that occur during maturation that cannot be accounted for by BMI. However, in the current study we measured body composition directly and reported similar findings.

It is difficult to explain why it is that walking behavior does not predict health status in this population, when this is not the case for children, and indeed adolescent boys. ${ }^{16}$ It is feasible that in fact daily step counts and activity levels of the girls were essentially too low for even the more active to achieve health benefits. In comparison to the mean daily step count values for the adolescent boys in the study by Dollman et al., ${ }^{16}$ the girls in the current study took approximately 800 fewer steps $\cdot$ day $^{-1}\left(10,287\right.$ compared to $\left.11,150 \mathrm{steps}^{\circ} \mathrm{day}^{-1}\right)$, which may be the equivalent to approximately 6-7minutes of MVPA per day (assuming a MVPA step rate of 120 steps $\left.\cdot \mathrm{min}^{-1}\right)$. Similarly in comparison to the younger girls (5-12yr olds), the girls in the current study took approximately 1300 fewer steps $\cdot$ day $^{-1}(10,287$ compared to 11,666 steps $\cdot$ day $^{-1}$ ), equivalent to approximately 10 minutes MVPA per day. However it should be noted that the mean daily step values and step cut points reported by Dollman et al., ${ }^{16}$ are lower than those proposed by other youth studies with the exception of Laurson et al., ${ }^{14}$ thus the difference in the number of steps $\cdot$ day $^{-1}$ between younger and older girls may in fact be greater. 
It is also possible that the health indicators adopted here did not appropriately represent health risk. Other than BMI (discussed above), percentage body fat (\%BF) is the only other health indicator (criterion) that has been previously employed to reference daily step recommendations in youth. ${ }^{12}$ Duncan et al., ${ }^{27}$ suggested that $\%$ BF may be a more appropriate health indicator to reference step recommendations against as it is more strongly associated with steps $\cdot$ day $^{-1}$ than BMI. However Andersen et al., ${ }^{38}$ stated that health outcomes are often unclear in the youth population, as the association between physical activity and single health risk indicators are often weak. They also suggested that a more appropriate measure of health status would be to calculate the level of health risk, by clustering disease risk factors, specifically cardiovascular risk factors. ${ }^{38}$ Therefore in the current study two separate health profiles (cluster risk scores) were calculated in addition to the single health indicators. The health profiles consisted of either BMI or \%BF as weight components, WC and BP as cardiovascular risk factors. Although no fitness related components or blood risk factors such as total cholesterol and HDL ratio were considered, Andersen et al., ${ }^{39}$ stated that lower intensity activities, such as walking have a greater effect on energy expenditure and insulin levels, than fitness per se. Therefore the health indicators used in this study, although mainly weight related should have been appropriate health indicators for activities such as walking.

\section{Steps and Activity time}

A further factor considered in the current study was whether the number of steps taken (volume of walking) or time in activity (intensity of walking/active stepping) was a better predictor of health status. It was hypothesised that the inclusion of activity time would be more likely to influence health status, as there is evidence to suggest that time spent in more vigorous physical activity better predicts adiposity than the total volume of activity, ${ }^{40}$ and 
that additional health benefits are gained from moderate to vigorous activity. ${ }^{1}$ However the current study demonstrated that as with the daily step counts, there was no difference in activity time between those classified as healthy and unhealthy among adolescent girls. Despite this, the current study is the first to consider active stepping (activity time) in addition to volume of walking (daily step counts) and such outcome measures may be worth considering in other populations

Further it is acknowledged that activity time was determined by pedometer (NL-1000) in the current study and therefore time in different intensities is unquantifiable (only activity at or above the 3.6 METs (NL-1000- level 4) was accumulated). While walking activity is unlikely to be undertaken at a pace that will promote higher intensities (METs), it remains unclear whether individuals classified as healthy continually walked at a higher intensity for similar periods of time as unhealthy individuals. This is considered a limitation to the current study.

\section{Comparison of current step recommendations}

The inability to be able to suggest a step count threshold that is relevant for adolescent girls returns the question as to whether current thresholds recommended for young people are at all appropriate for this population. The ability for currently published guidelines to be able to correctly discriminate between girls that were 'healthy' and 'unhealthy' was therefore examined. The lowest step cut point of 10,000 steps $\cdot$ day $^{-1}{ }^{14}$ consistently produced the greatest Se and Sp values for BMI, \%BF, HP1 and HP2 compared to the other recommendations ${ }^{14,17,25,27}$ and thus could be considered the most appropriate recommendation to use in adolescent girls. However, even using this 'best case' threshold, 
$34 \%$ of girls classified as 'healthy' according to BMI did not meet the recommendation and $46 \%$ of 'unhealthy' girls did meet the recommendation.

In a recent review of all previously published step recommendations, and whilst acknowledging the weaknesses of published thresholds, Tudor-Locke et al., ${ }^{6}$ suggested that 10-11,700 steps $\cdot$ day $^{-1}$ may be an appropriate recommendation for daily steps for adolescent boys and girls. Interestingly, this was proposed as it was intermediate to the recommended steps $\cdot$ day $^{-1}$ for children and adults, and was therefore inherently logical. Whilst this study has demonstrated that such a threshold may be misleading, 10,000 steps $\cdot$ day $^{-1}$ appears to be the best informed guideline to use to date.

\section{Strengths and Limitations}

This is the first study to consider time spent in activity $\left(\right.$ mins $\cdot$ day $\left.^{-1}\right)$ in addition to steps $\cdot$ day $^{-1}$ to explore how much walking is required for health. It is also the first to report step based data relating to $\mathrm{WC}$ and blood pressure as single health indicators and to use health profiles in order to categorise health status, and thus avoid the limitations of any one indicator alone

Limitations of this study are the relatively small number of participants classified in each health category, compared to previous youth studies. Further participants excluded from final analysis (reasons outlined in figure 1) were significantly heavier and had significantly greater BMI than those included in the final analysis, suggesting that the study has selected a healthier sample. Although the study employed more sophisticated measures of health than prior youth studies and the pedometers used, had the ability to provide a practical and affordable way to communicate walking activity in terms of steps $\cdot$ day $^{-1}$ and activity time e.g. time spent at or above pre-specified intensity thresholds (steps $\cdot \mathrm{min}^{-1}$ ). ${ }^{6,11} \mathrm{It}$ is acknowledged 
that pedometer determined PA is limited and as such may not provide enough information to discriminate health status. ${ }^{15}$ Further, and as indicated in previous youth studies, ${ }^{14,16}$ it is not possible to determine if health status is an outcome or cause of pedometer determined steps and activity time due to the cross sectional design of the current study.

\section{Conclusion}

In conclusion results of the current study indicate that in terms of walking activity, 'healthy' adolescent girls do not walk significantly more in term of steps $\cdot$ day ${ }^{-1}$ or time spent in activity than girls classified as 'unhealthy'. A possible explanation for this is that adolescent girls may not walk enough to stratify health and health related outcomes and as a result, the data could not be used to inform an appropriate step guideline for this population. Considering previously defined thresholds and acknowledging their limitations, it appears that the best guideline to adopt might be $10,000 \mathrm{step} \cdot \mathrm{day}^{-1}$. However, further research is required to inform intervention as to both the quantity and quality of walking required to advocated good health in adolescent girls. 


\section{References}

1. Department of Health. Start active, stay active: a report on physical activity from the four home countries' Chief Medical Officers. UK2011.

2. World Health Organisation (WHO). 2015 title of page [online]Available from http://www.who.int/mediacentre/factsheets/fs385/en/ [accessed $17^{\text {th }}$ May 2016]

3. Morris JN, Hardman AE. Walking to health. Sports Med. 1997;23(5):306-32.

4. Carlin A, Murphy MH, Gallagher AM. Do interventions to increase walking work? A systematic review of interventions in children and adolescents. Sports Med. 2016;46 $515-530$

5. Carlin A, Murphy MH, Gallagher AM. Current influences and approaches to promote future physical activity in 11-13year olds: a focus group study. BMC Public Health. $2015 ; 15: 1270$

6. Tudor-Locke C, Craig CL, Beets MW, et al. How many steps/day are enough? for children and adolescents. Int J Behav Nutr Phys Act. 2011;8:78.

7. Tudor-Locke C, Bassett DR, Jr. How many steps/day are enough? Preliminary pedometer indices for public health. Sports Med. 2004;34(1):1-8.

8. Tudor-Locke C, Ham SA, Macera CA, et al. Descriptive epidemiology of pedometerdetermined physical activity. Med Sci Sports Exerc. 2004 ;36(9):1567-73.

9. Tudor-Locke C, Hatano Y, Pangrazi RP, Kang M. Revisiting 'how many steps are enough?'. Med Sci Sport Exerc. 2008 ; 40 (7 suppl): S537-43

10. Tudor-Locke C, McClain JJ, Hart TL, Sisson SB, Washington TL. Expected values for pedometer-determined physical activity in youth. Res Q Exerc Sport. 2009; 80(2):16474.

11. Beets MW, Bornstein D, Beighle A, Cardinal BJ, Morgan CF. Pedometer-measured physical activity patterns of youth: a 13-country review. Am J Prev Med. 
2010;38(2):208-16

12. Duncan JS, Schofield G, Duncan EK. Step count recommendations for children based on body fat. Prev Med. 2007 ;44(1):42-4.

13. Tudor-Locke C, Pangrazi RP, Corbin CB, et al. BMI-referenced standards for recommended pedometer-determined steps/day in children. Prev Med. 2004;38(6):85764.

14. Laurson KR, Eisenmann JC, Welk GJ, Wickel EE, Gentile DA, Walsh DA. Evaluation of youth pedometer-determined physical activity guidelines using receiver operator characteristic curves. Prev Med. 2008;46(5):419-24.

15. Beets MW, Le Masurier GC, Beighle A, et al. Are current body mass index referenced pedometer step-count recommendations applicable to US youth? J Phys Act Health. 2008;5(5):665-74.

16. Dollman J, Olds TS, Esterman A, Kupke T. Pedometer step guidelines in relation to weight status among 5- to 16-year-old Australians. Pediatr Exerc Sci. 2010;22(2):288300.

17. McCormack GR, Rutherford J, Giles-Corti B, Tudor-Locke C, Bull F. BMI-referenced cut-points for recommended daily pedometer-determined steps in Australian children and adolescents. Res Q Exerc Sport. 2011;82(2):162-7.

18. Shah NR, Braverman ER (2012) Measuring Adiposity in Patients: The Utility of Body Mass Index (BMI), Percent Body Fat, and Leptin. PLoS ONE 7(4) doi: 10 1371/journal.pone.0033308 Accessed 10 March 2015.

19. Stewart, A., Marfell-Jones, M., Olds, T., DeRidder, H. International Standards for Athropometric Assessment. International Society for the Advancement of Kinathropometry, Lower Hutt, New Zealand. December 2011 
20. McCarthy HD, Cole TJ, Fry T, Jebb SA, Prentice AM. Body fat reference curves for children. Int J Obes (Lond). 2006;30(4):598-602.

21. Mirwald RL, Baxter-Jones AD, Bailey DA, Beunen GP. An assessment of maturity from anthropometric measurements. Med Sci Sports Exerc. 2002. 34(4):689-94

22. Cole TJ, Bellizzi MC, Flegal KM, Dietz WH. Establishing a standard definition for child overweight and obesity worldwide: international survey. BMJ. 2000;320(7244):1240-3.

23. McCarthy HD, Jarrett KV, Crawley HF. The development of waist circumference percentiles in British children aged 5.0-16.9 y. Eur J Clin Nutr. 2001;55(10):902-7.

24. National institutes for health (NIH), National heart, lung and blood institute (NHLBI), US Department of Health and Human services 2007.

25. Vincent SD, Pangrazi RP. An Examination of the Activity Patterns of Elementary School Children. Pediatr Exerc Sci. 2002;14(4):432-41.

26. Strycker LA, Duncan SC, Chaumeton NR, Duncan TE, Toobert DJ. Reliability of pedometer data in samples of youth and older women. Int J Behav Nutr Phys Act. $2007 ; 4: 4$.

27. Duncan JS, Schofield G, Duncan EK. Pedometer-determined physical activity and body composition in New Zealand children. Med Sci Sport Exerc. 2006, 38 (8), 1402-9

28. Murphy MH, Hardman AE. Training effects of short and long bouts of brisk walking in sedentary women. Med Sci Sports Exerc. 1998;30(1):152-7.

29. Woolf-May K, Kearney EM, Owen A, Jones DW, Davison RCR, Bird SR. The efficacy of accumulated short bouts versus single daily bouts of brisk walking in improving aerobic fitness and blood lipid profiles. Health Educ Res. 1999;14(6):803-15.

30. Rowe D, Mahar MT, Raedeke TD, Lore J. Measuring physical activity in children with pedometers: Reliability, reactivity and replacement of missing data. Pediatr Exerc Sci, 
2004, 16, 343-354.

31. Tabachmik, B.J., Fidell, L.S., Using Multivarite Statistics 5th Ed. California state University, Northridge, USA.

32. Safrit MJ. Introduction to measurement in physical education and exercise science. St. Louis: (MO): Mosby College Publishing; 1986.

33. Berk RA. Determination of optimal cutting scores in criterion referenced measurement. Journal of Experimental Education. 1976;45:4-9

34. Cohen J. Statistical power analysis for the behavioral sciences (2nd ed.). Hillsdale, NJ: Lawrence Earlbaum Associates. 1988.

35. Mendoza JA, Nicklas TA, Lui Y, Stuff J, Baranowski T. General versus Central Adiposity and Relationship to Paediatric Metabolic Risk. MetabSyndr Relat Disord. 2012 10(2):128-136

36. Mahoney LT, Burns TL, Stanford W. et al. Coronary risk factors measured in childhood and young adult life are associated with coronary artery calcification in young adults. $J$ Am Cell Cardiol.1996;27:277-284.

37. Levine JA, Vander Weg MW, Hill JO, Klesges RC. Non-exercise activity thermogenesis: the crouching tiger hidden dragon of societal weight gain. Arterioscler Thromb Vasc Biol. 2006;26(4):729-36.

38. Andersen LB, Boreham CA, Young IS, et al. Insulin sensitivity and clustering of coronary heart disease risk factors in young adults. The Northern Ireland Young Hearts Study. Prev Med. 2006;42(1):73-7.

39. Andersen LB, Sardinha LB, Froberg K, Riddoch CJ, Page AS, Sigmund A. Fitness, fatness and clustering of cardiovascular risk factors in children from Denmark, Estonia and Portugal: the European Youth Heart Study. Int J Pediatr Obes. 2008;3 Suppl 1:5866. 
40. Ruiz JR, Rizzo NS, Hurtig-Wennlöf A, Ortega FB, Wärnberg J, Sjöström M. Relations of total physical activity and intensity to fitness and fatness in children: the European Youth Heart Study. Am J Clin Nutr. 2006;84(2):299-303.

\section{Funding Source}

This study was funded by the Scottish Physical Activity Research Collaboration's (SPARColl), a research collaboration funded by the Scottish Government. 


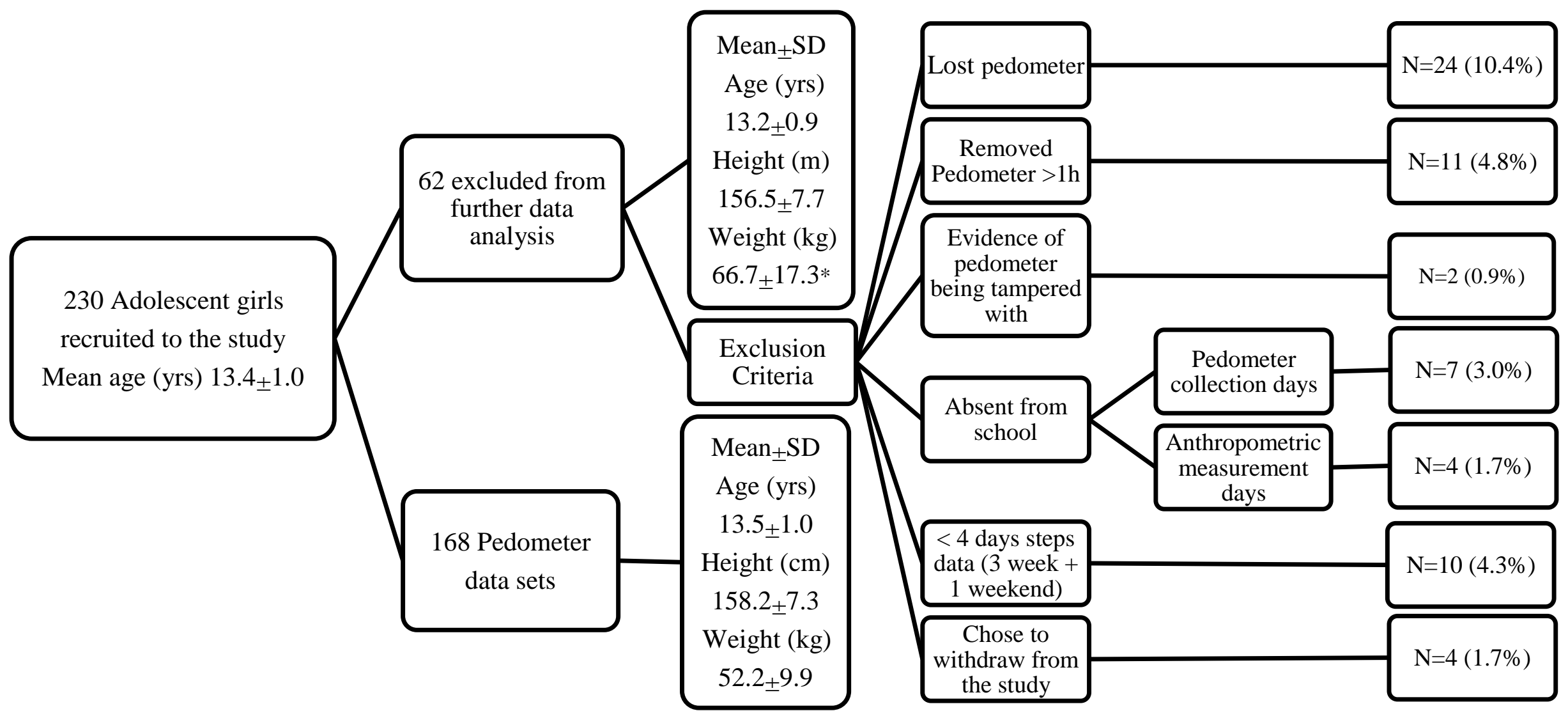

Figure 1. Participant numbers recruited, exclusion criteria and dropout rates

* significantly heavier than the girls included in analysis $(p<0.01)$ 
Table.1. Physical characteristics

\begin{tabular}{llll}
\hline Variable & N & Mean \pm SD & Range \\
\hline Age (yrs) & 168 & $13.5 \pm 1.0$ & $12.6-15.8$ \\
Height (cm) & 168 & $158.26 \pm 7.30$ & $137.50-178.20$ \\
Weight (kg) & 168 & $52.18 \pm 9.90$ & $34.00-75.00$ \\
Maturity offset (yrs) & 168 & $0.6 \pm 0.9$ & $-1.5-2.3$ \\
Body Mass Index (BMI) & 168 & $20.46 \pm 3.99$ & $13.60-37.20$ \\
Waist Circumference (cm) & 168 & $67.16 \pm 8.35$ & $50.20-105.00$ \\
Body Fat (\%) & 116 & $27.31 \pm 6.31$ & $12.40-50.50$ \\
Systolic Blood Pressure & 139 & $117 \pm 14$ & $87-166$ \\
Diastolic Blood Pressure & 139 & $71 \pm 10$ & $42-96$ \\
\hline
\end{tabular}


Table 2. Mean daily step counts (steps·day $\left.{ }^{-1}\right)$ and activity time $\left(\right.$ mins $\left.^{\cdot d a y}{ }^{-1}\right)$ for each health indicator, health profile and health category.

\begin{tabular}{|c|c|c|c|c|c|c|c|c|c|c|c|c|}
\hline \multirow[b]{2}{*}{ Health Status } & \multicolumn{2}{|c|}{ BMI } & \multicolumn{2}{|c|}{ Waist Circumference } & \multicolumn{2}{|c|}{ Percentage Body Fat } & \multicolumn{2}{|c|}{ Blood Pressure } & \multicolumn{2}{|c|}{ Health Profile 1} & \multicolumn{2}{|c|}{ Health Profile 2} \\
\hline & Healthy & Unhealthy & Healthy & Unhealthy & Healthy & Unhealthy & Healthy & Unhealthy & Healthy & Unhealthy & Healthy & Unhealthy \\
\hline \multirow[t]{2}{*}{$\mathbf{N}$} & 105 & 63 & 92 & 76 & 81 & 35 & 85 & 54 & 101 & 35 & 82 & 34 \\
\hline & $19.3 \pm 1.6$ & $22.3 \pm 5.7$ & $62.1 \pm 3.2$ & $73.3 \pm 8.51$ & $24.1 \pm 3.1$ & $34.3 \pm 5.9$ & $108.9 \pm 7.6$ & $132.1 \pm 14.8$ & - & - & - & - \\
\hline \multicolumn{13}{|l|}{ Mean } \\
\hline Percentage & 62.50 & 37.50 & 54.82 & 45.18 & 69.82 & 31.03 & 61.15 & 38.84 & 74.26 & 25.74 & 70.69 & 29.31 \\
\hline $\begin{array}{l}{\text { Steps} \cdot \text { day }^{-1}}^{\text {Effect size }}\end{array}$ & $\begin{array}{l}10666 \\
\pm 2947 \\
d=0.27\end{array}$ & $\begin{array}{l}9841 \\
\pm 2984\end{array}$ & $\begin{array}{l}10593 \\
\pm 3211 \\
d=0.19\end{array}$ & $\begin{array}{l}10026 \\
\pm 2671\end{array}$ & $\begin{array}{l}10641 \\
\pm 3071 \\
d=0.28\end{array}$ & $\begin{array}{l}9742 \\
\pm 3165\end{array}$ & $\begin{array}{l}10176 \\
\pm 2956 \\
d=0.15\end{array}$ & $\begin{array}{l}10648 \\
\pm 3291\end{array}$ & $\begin{array}{l}10532 \\
\pm 2736 \\
d=0.21\end{array}$ & $\begin{array}{l}9863 \\
\pm 3567\end{array}$ & $\begin{array}{l}10500 \\
\pm 2855 \\
d=0.21\end{array}$ & $\begin{array}{l}10058 \\
\pm 3692\end{array}$ \\
\hline $\begin{array}{l}\text { Mins'day }^{-1} \\
\text { Effect size }\end{array}$ & $\begin{array}{l}42.76 \\
\pm 17.55 \\
d=0.29\end{array}$ & $\begin{array}{l}37.84 \\
\pm 15.40\end{array}$ & $\begin{array}{l}43.20 \\
\pm 18.13 \\
d=0.31\end{array}$ & $\begin{array}{l}38.04 \\
\pm 15.01\end{array}$ & $\begin{array}{l}43.90 \\
\pm 18.11 \\
d=0.27\end{array}$ & $\begin{array}{l}38.97 \\
\pm 17.58\end{array}$ & $\begin{array}{l}39.61 \\
\pm 15.93 \\
d=0.17\end{array}$ & $\begin{array}{l}42.71 \\
\pm 19.4\end{array}$ & $\begin{array}{l}42.14 \\
\pm 16.51 \\
d=0.26\end{array}$ & $\begin{array}{l}37.64 \\
\pm 17.28\end{array}$ & $\begin{array}{l}43.59 \\
\pm 17.39 \\
d=0.22\end{array}$ & $\begin{array}{l}39.54 \\
\pm 19.36\end{array}$ \\
\hline
\end{tabular}

Unhealthy= individuals classified as at 'health risk' e.g. underweight, overweight, obese, pre-hypertensive and hypertensive 
Health profile 1 = Cluster score of Body Mass Index, Waist Circumference and Blood Pressure

Health profile $2=$ Cluster score of $\%$ body fat, Waist Circumference and Blood Pressure 
Table 3 Evaluation of previously published step count recommendations for two health indicators (BMI and \% BF) and health profiles

\begin{tabular}{|c|c|c|c|}
\hline Health reference & Step Cut point (steps $\cdot$ day $^{-1}$ ) & Sensitivity (Se) & Specificity (Sp) \\
\hline \multirow[t]{5}{*}{ BMI } & $10,000^{\mathrm{a}}$ & 0.64 & 0.46 \\
\hline & $11,000^{\mathrm{b}}$ & 0.35 & 0.24 \\
\hline & $12,000^{\mathrm{c}}$ & 0.28 & 0.18 \\
\hline & $13,000^{\mathrm{d}}$ & 0.17 & 0.14 \\
\hline & $16,000^{\mathrm{e}}$ & 0.38 & 0.63 \\
\hline \multirow[t]{5}{*}{$\% \mathrm{BF}$} & $10,000^{\mathrm{a}}$ & 0.58 & 0.49 \\
\hline & $11,000^{\mathrm{b}}$ & 0.46 & 0.34 \\
\hline & $12,000^{\mathrm{c}}$ & 0.35 & 0.26 \\
\hline & $13,000^{\mathrm{d}}$ & 0.26 & 0.17 \\
\hline & $16,000^{\mathrm{e}}$ & 0.49 & 0.57 \\
\hline \multirow[t]{5}{*}{ HP1 } & $10,000^{\mathrm{a}}$ & 0.60 & 0.50 \\
\hline & $11,000^{\mathrm{b}}$ & 0.47 & 0.36 \\
\hline & $12,000^{\mathrm{c}}$ & 0.32 & 0.27 \\
\hline & $13,000^{\mathrm{d}}$ & 0.26 & 0.18 \\
\hline & $16,000^{\mathrm{e}}$ & 0.40 & 0.68 \\
\hline \multirow[t]{5}{*}{ HP2 } & $10,000^{\mathrm{a}}$ & 0.58 & 0.47 \\
\hline & $11,000^{\mathrm{b}}$ & 0.46 & 0.35 \\
\hline & $12,000^{\mathrm{c}}$ & 0.33 & 0.29 \\
\hline & $13,000^{\mathrm{d}}$ & 0.22 & 0.27 \\
\hline & $16,000^{\mathrm{e}}$ & 0.49 & 0.59 \\
\hline
\end{tabular}

$\mathrm{BMI}=$ Body Mass Index, $\% \mathrm{BF}=$ Percentage Body fat, $\mathrm{HP} 1=$ Health profile $1, \mathrm{HP}=$ Health Profile 2

Step cut points $a=$ Laurson et al., ${ }^{11}$ (5-12yr olds), b=Vincent and Pangrazi., ${ }^{21}$ (5-11yr olds), $\mathrm{c}=$ Tudor-Locke et al., ${ }^{10}$ (6-12yr olds), d=Duncan et al., ${ }^{9}$ (5-12yr olds), e=McCormack et al., ${ }^{14}$ (7-16yr olds) 
Table 4. Percentage (\%) of the girls meeting selected step defined cut points Step cut point All girls $12(n=69) \quad 13(n=38) \quad 14(n=47) \quad 15(n=14)\left(\right.$ steps $^{\circ}$ day $\left.^{-1}\right)$ $(\mathbf{n}=\mathbf{1 6 8})$

$\begin{array}{lllll}57 & 63 & 52 & 55 & 50\end{array}$

$10,000^{\mathrm{a}}$

$11,000^{b}$

44

49

42

38

42

12,000 c

30

31

26

31

35

$13,000^{d}$

23

18

26

26

28

$16,000^{e}$

4

0

5

8

14

Step cut points $a=$ Laurson et al., ${ }^{11}$ (5-12yr olds), $b=$ Vincent and Pangrazi., ${ }^{21}$ (5-11yr olds), $\mathrm{c}=$ Tudor-Locke et al., ${ }^{10}$ (6-12yr olds), d=Duncan et al., ${ }^{9}$ (5-12yr olds) e=McCormack et al., ${ }^{14}$ (7-16yr olds).

Step cut points $-\mathrm{a}, \mathrm{c}$ and $\mathrm{e}=\mathrm{BMI}$ referenced, $\mathrm{b}=$ Norm referenced, $\mathrm{d}=\%$ Body fat referenced. 
Walking for health 